REALA, número 12, octubre-marzo de 2019

Sección: COMUNICACIONES Y COMENTARIOS JURISPRUDENCIALES

Recibido: 09-08-2019

Modificado: 23-09-2019

Aceptado: 23-09-2019

DOI: 10.24965/reala.i12.10712

Páginas: 152-164

\title{
Nulidad radical de un Acuerdo municipal de apoyo al proceso soberanista catalán (Sentencia del Tribunal Supremo núm. 2088/2019, de 26 de junio) ${ }^{1}$
}

\author{
Automatic nullity of a municipal act supporting the Catalonian \\ Procès (Spanish Supreme Court's Sentence 2088/2019, \\ of $26^{\text {th }}$ June)
}

\author{
Gustavo Manuel Díaz González \\ Universidad de Oviedo (España) \\ ORCID: https://orcid.org/0000-0003-4796-2883 \\ diazgustavo@uniovi.es
}

\section{NOTA BIOGRÁFICA}

Doctor en Derecho por las Universidades de Bolonia (2015) y Oviedo (2018) y Profesor Ayudante Doctor de Derecho Administrativo de la Universidad de Oviedo. Durante los cursos 2016/2017 y 2017/2018 trabajó como Investigador Postdoctoral en la Cátedra de Derecho Constitucional, Administrativo, Europeo y Comparado de la Universidad de Constanza dirigida por el Prof. Dr. D. Hans C. Röhl. Es miembro del Grupo de Investigación «Derecho Administrativo (DA)» de la Universidad de Oviedo, dirigido por el Prof. Dr. D. Alejandro Huergo Lora. Sus principales líneas de investigación son el sistema de fuentes y la internacionalización del Derecho Público.

\section{RESUMEN}

El Tribunal Supremo ha declarado, por virtud de la sentencia núm. 2088/2019, de 26 de junio, la nulidad de pleno derecho de un Acuerdo del Pleno del municipio de Caldes de Montbui en el que se proclamaba la adhesión de la corporación al proceso soberanista catalán. Aun alcanzando una conclusión acertada, la Sentencia adolece de importantes debilidades argumentales, toda vez que, de una parte, en ella se adopta una postura excesivamente restrictiva en relación con las posibilidades de actuación estrictamente política de los ayuntamientos y, de otra, no se consideran diversos elementos de juicio relevantes para la resolución del recurso, que habrían permitido una mejor justificación de la declaración de nulidad del Acuerdo impugnado.

\section{PALABRAS CLAVE}

Autonomía local; acto de gobierno; competencias municipales; Procès catalán; vinculación positiva a la ley.

\section{ABSTRACT}

Spanish Supreme Court's Sentence 2088/2019, of $26^{\text {th }}$ June, has upheld the appeal of invalidity of an act which had declared the support of the municipality of Caldes de Montbui to the Independence of Catalonia.

1 El presente trabajo ha sido realizado en el marco del proyecto de investigación de referencia FC-GRUPIN-IDI/2018/000202 de la Consejería de Empleo, Industria y Turismo del Principado de Asturias, cuyo Investigador Principal es el Prof. Dr. D. José Pedreira Menéndez. 
REALA. Nueva Época - N. ${ }^{0}$ 12, octubre-marzo 2019 - ISSN: 1989-8975 - DOI: 10.24965/reala.i12.10712 - [Págs. 152-164]

Nulidad radical de un Acuerdo municipal de apoyo al proceso soberanista catalán (Sentencia del Tribunal Supremo núm. 2088/2019...

Though having reached to the right solution, the Sentence is not completely well-founded, since, on the one hand, it is based on a very restrictive understanding of the capacity of local entities in order to develop their strictly political activities, and, on the other hand, it does not take into account some other aspects which could have been the basis for a better legal reasoning.

\section{KEYWORDS}

Local self-government; governmental act; municipal competences; Catalonian Procès; positive binding to the law.

\section{SUMARIO}

I. INTRODUCCIÓN. II. SÍNTESIS DEL TRATAMIENTO JURISPRUDENCIAL DEL ACUERDO DEL PLENO DEL MUNICIPIO DE CALDES DE MONTBUI, CON ESPECIAL REFERENCIA A LA SENTENCIA DEL TRIBUNAL SUPREMO DE 26 DE JUNIO DE 2019. III. COMENTARIO CRÍTICO DE LA RESOLUCIÓN. 1. UN RECHAZO CERTERO, AUNQUE UN TANTO TÍMIDO, DE LA APLICACIÓN DE LAS RESTRICCIONES DEL CONTROL JURISDICCIONAL DE LOS ACTOS DE GOBIERNO. 2. UNAAPLICACIÓN NO MATIZADA Y FALTA DE PRECEDENTES DE LOS PRINCIPIOS DE COMPETENCIA Y LEGALIDAD A LA ACTIVIDAD MERAMENTE DECLAMATORIA DE LAS ENTIDADES LOCALES. 3. UN OLVIDO PATENTE DE DIVERSOS CRITERIOS ADICIONALES DE ARGUMENTACIÓN. IV. CONCLUSIONES. V. BIBLIOGRAFÍA.

\section{INTRODUCCIÓN}

El Tribunal Supremo ha escrito recientemente una de las páginas jurídicas más interesantes del, en términos políticos, al menos para el autor de estas líneas, ya muy tedioso proceso soberanista catalán. Por virtud de la Sentencia núm. 2088/2019, de 26 de junio, cuya doctrina reproducen íntegramente dos resoluciones posteriores ${ }^{2}$, la Sección $4 .^{a}$ de la Sala $3 .^{a}$ del Alto Tribunal ha declarado la nulidad de pleno derecho, por falta manifiesta de competencia, del Acuerdo del Pleno del municipio de Caldes de Montbui de 28 de febrero de 2013, en el que, en esencia, se manifestaba el apoyo de la corporación a la autodeterminación de la Comunidad Autónoma catalana. Concluye así el periplo jurisdiccional de una resolución que las instancias procesales inferiores habían valorado de forma dispar: así, mientras que el Juzgado de lo ContenciosoAdministrativo núm. 13 de Barcelona había estimado íntegramente el recurso interpuesto frente al Acuerdo por el Delegado del Gobierno en la Comunidad Autónoma (Sentencia núm. 95/2014, de 25 de marzo), la Sección 5. ${ }^{a}$ de la Sala de lo Contencioso-Administrativo del Tribunal Superior de Justicia de Cataluña había adoptado una postura que se pretendía más equilibrada, al entender que tan solo una parte de la resolución controvertida trascendía el contexto estrictamente político, desplegando auténticos efectos jurídicos, y que, por consiguiente, tan solo a dicha parte debía afectar la declaración de nulidad (Sentencia núm. 522/2017, de 26 de junio). El Tribunal Supremo, en los términos que seguidamente se verán, ha casado la Sentencia del Tribunal Superior de Justicia y confirmado la del Juzgado.

Lo delicado de la problemática política subyacente y la falta de precedentes jurisprudenciales inmediatos aconsejaban que la resolución del recurso se llevara a cabo con un particular esfuerzo de motivación. No ha obrado así, en nuestra opinión, el Tribunal Supremo: como habrá de ponerse de manifiesto en la exposición sucesiva, el Alto Tribunal ha adoptado una comprensión sumamente restrictiva de las posibilidades de actuación estrictamente política de los ayuntamientos, basándose en una lectura inflexible de los principios de legalidad y competencia y obviando no solo algunas resoluciones previas en las que se había partido de una lectura más matizada de los mismos, sino también diversas líneas de razonamiento que, desde nuestro punto de vista, habrían permitido una más correcta justificación de la declaración de nulidad del Acuerdo municipal impugnado. Ello nos mueve a exponer, en las páginas que siguen, tras una referencia sucinta a las diferentes líneas de argumentación en que se han basado los distintos órganos judiciales que han conocido del asunto (II), nuestra propia visión sobre el particular (III). Cerraremos nuestro trabajo con la formulación de unas breves conclusiones (IV).

2 Sentencias de la Sección $4 .^{a}$ de la Sala $3 .^{a}$ del Tribunal Supremo núm. 937/2018, de 28 de junio, y núm. 448/2019, de 1 de julio, que declaran, igualmente, la nulidad de pleno derecho de sendos Acuerdos municipales de contenido similar al controvertido en la resolución objeto de comentario. 


\section{SÍNTESIS DEL TRATAMIENTO JURISPRUDENCIAL DEL ACUERDO DEL PLENO DEL MUNICIPIO DE CALDES DE MONTBUI, CON ESPECIAL REFERENCIA A LA SENTENCIA DEL TRIBUNAL SUPREMO DE 26 DE JUNIO DE 2019}

El Acuerdo del Pleno del municipio de Caldes de Montbui incorporaba un contenido complejo, en el sentido de que no se limitaba a una adhesión ideológica al proceso soberanista catalán, sino que incluía varias declaraciones de alcance diverso -lo que, como se ha destacado supra, motivó la declaración de la nulidad solo parcial del Acuerdo por parte del Tribunal Superior de Justicia-. El Acuerdo proclamaba, en primer lugar, la caracterización del municipio como territorio catalán, libre y soberano (apdo. 1); declaraba, asimismo, que la voluntad mayoritaria de sus ciudadanos era la de que la soberanía fuera ejercida por el Estado libre y soberano (apdo. 2); solicitaba al Parlament de Cataluña que avanzase para la consecución de este objetivo y que, entretanto, gestionara los problemas de la sociedad catalana, con vistas al referido futuro independiente y con especial consideración de los ciudadanos más necesitados (apdo. 3); y acordaba, por último, hacer públicas tales declaraciones, a fin de que este paso adelante animara a otros municipios a hacer lo propio y para solidarizarse con quienes estaban viéndose asediados por haberse manifestado de manera similar (apdo. 4) ${ }^{3}$.

Por Sentencia núm. 95/2014, de 25 de marzo, el Juzgado de lo Contencioso-Administrativo núm. 13 de Barcelona estimó íntegramente el recurso interpuesto frente a la resolución municipal por la Delegación del Gobierno en Cataluña. De acuerdo con la síntesis que, al respecto, ofrece la Sentencia del Tribunal Supremo objeto de comentario en su Antecedente de Hecho tercero, el Juzgado razonó en los siguientes términos: en primer lugar, el Acuerdo municipal impugnado habría de ser considerado como una forma de actividad administrativa impugnable, por no faltarle habilidad para la producción de efectos jurídicos frente a terceros ni ser posible su caracterización como acto político no susceptible de control; en segundo lugar, el Acuerdo sería revelador del propósito de llevar a cabo una alteración del marco constitucional al margen de los procedimientos establecidos; en tercer lugar, faltaría al municipio cualquier atribución legal, exigible de acuerdo con lo establecido en el artículo 25.2 de la Ley 7/1985, de 2 de abril, reguladora de las bases del régimen local (en adelante, LBRL), de la competencia para la adopción de un Acuerdo como el controvertido, de imposible conexión, además, con la esfera de actuación autónoma que se encuentra constitucionalmente garantizada a favor de las entidades locales; y, por último, el Acuerdo resultaría «paradigmático» del exceso competencial municipal, dada su incidencia sobre aspectos constitucionales basilares (titularidad de la soberanía, integridad territorial del Estado y precisión de sus fronteras, relaciones internacionales, organización territorial del Estado y derechos y libertades de sus ciudadanos); motivos todos ellos por los cuales declaraba la nulidad de pleno derecho del Acuerdo por falta manifiesta de competencia.

Frente a esta Sentencia interpuso la representación procesal del Ayuntamiento de Caldes de Montbui recurso de apelación ante el Tribunal Superior de Justicia de Cataluña con base en los argumentos siguientes: (i) el Acuerdo constituiría una declaración adoptada por un órgano de representación democrática y poseería un carácter netamente político, lo que determinaría su no sujeción al Derecho administrativo, su inhabilidad para producir efectos jurídicos (en el sentido de dar lugar a la extinción o modificación de derechos u obligaciones), y, consiguientemente, la imposibilidad de su impugnación jurisdiccional; (ii) al Acuerdo no podrían tampoco asociarse desarrollos futuros, al carecer el municipio y sus miembros de la potestad de participación en un diálogo o negociación institucionales con vistas a la revisión del marco constitucional y al no prever aquel actuaciones subsiguientes; (iii) en último término, la resolución habría de ser considerada como una forma de ejercicio del derecho de petición.

Como se ha adelantado, el Tribunal Superior de Justicia acordó, en su Sentencia núm. 522/2017, de 26 de junio, la estimación parcial del recurso de apelación, limitando la declaración de nulidad a los dos primeros apartados del Acuerdo municipal controvertido. La resolución del recurso había de partir, en opinión del Tribunal, de la comprensión siguiente: en modo alguno era discutible que el Acuerdo municipal incorporase

3 El tenor literal del Acuerdo, reproducido por la Sentencia del Tribunal Supremo en el primer Antecedente de Hecho, era, además de la que se describe como una amplia exposición introductoria, el siguiente: «1. Declarar que el municipi de Caldes de Montbui es territori català lliure i sobirà. 2. Declarar que la voluntat majoritaria del seus ciutadans és que aquesta sobirania sigui exercida per un nou estat lliure i sobirá. 3. Demanar al Parlament de Catalunya que traballi per aconseguir aquesta fita com abans millor, i que entre tanti gestioni la solució des problemes que afronta Catalunya, pensant en aquest futur i en el present del mes necessitats del seus ciutadans. 4. Fer publics aquests acords, com a incentiu per altres municipis i com a solidaritat amb aquellos que están assetjats per haver-se manifestat en forma similar». 
REALA. Nueva Época - N. 12, octubre-marzo 2019 - ISSN: 1989-8975 - DOI: 10.24965/reala.i12.10712 - [Págs. 152-164]

Nulidad radical de un Acuerdo municipal de apoyo al proceso soberanista catalán (Sentencia del Tribunal Supremo núm. 2088/2019..

contenidos que entraban en colisión con el texto constitucional, hecho que ni siquiera la corporación autora del mismo contestaba; lo verdaderamente importante era, por el contrario, determinar si la resolución se limitaba al ámbito estrictamente político o si, en cambio, resultaba apta para la producción de auténticos efectos jurídicos, pues solo en el segundo caso procedería su control jurisdiccional, toda vez que, siempre en opinión del Tribunal Superior de Justicia, de conformidad con lo afirmado por el Tribunal Constitucional en su Sentencia 42/2014, de 25 de marzo, por la que se resolvió sobre la Declaración de Soberanía del Parlament catalán, «la mera suscripción de un enunciado inconstitucional no es un hecho que por sí mismo permita una fiscalización judicial (la mera subscripció d'un enunciat inconstitucional no és un fet que per sí sol permeti una fiscalització judicial)». El Acuerdo municipal poseería una base política incontrovertible, lo que no sería, sin embargo, motivo suficiente para excluir el control judicial, habida cuenta de que la vigente Ley 29/1998, de 13 de julio, reguladora de la jurisdicción contencioso-administrativa (en adelante, LJCA), ha consagrado la superación de la tradicional doctrina del acto político y la posibilidad de fiscalización del conjunto de la actividad de las Administraciones Públicas sometida al Derecho administrativo. Ello determinaría, en fin, la irrelevancia de las argumentaciones basadas en la libertad de expresión, en la existencia de una efectiva atribución de competencia municipal en la materia o en el principio de objetividad, pues el dato decisivo para entrar a analizar la posible invalidez del Acuerdo sería su aptitud para producir efectos jurídicos ${ }^{4}$.

Sobre la referida base argumental, y a partir de un recordatorio de la doctrina constitucional afirmada en la STC 42/2014, de 25 de marzo, que estimó aplicable al caso [en concreto, aquella por virtud de la que «el mero enunciado de una proposición contraria a la Constitución (...) no constituye objeto de enjuiciamiento por este Tribunal»], declaró el Tribunal Superior de Justicia que debían considerarse sujetos a control jurisdiccional los pasajes del Acuerdo recurrido «formulados materialmente como una resolución jurídica», esto es, los «que [tenían] un contenido asertivo e [incluían] una declaración formal que se proyecta[ba] sobre el estatuto jurídico de las instituciones o de las personas». "En nada cambiar[ía]n las cosas», proseguiría el Tribunal, por el hecho de que dichos pasajes poseyeran un «perfil simbólico», pues su anulación, de resultar aptos para la producción de efectos jurídicos, sería necesaria por estrictas razones de seguridad jurídica.

Esta sería la situación, concluiría el Tribunal Superior de Justicia, en que se encontraban los dos primeros apartados del Acuerdo impugnado, de los que resultaban la caracterización del municipio como territorio catalán, libre y soberano, y la afirmación de que la voluntad mayoritaria de sus ciudadanos era la de que dicha soberanía fuera ejercida por un nuevo Estado libre y soberano, no así la petición dirigida al Parlament ni la decisión de hacer públicas tales declaraciones, que no rebasarían el ámbito estrictamente político, debiendo considerarse, por lo tanto, excluidas del control judicial y, consiguientemente, afectadas favorablemente por la estimación parcial del recurso de apelación ${ }^{5}$.

En un escenario como el descrito -es decir, a la vista de dos resoluciones previas del asunto de signo diferente-, el Tribunal Supremo, que hubo de conocer del caso de resultas de la interposición de un recurso de casación por la Abogacía del Estado, ha acordado poner punto final a la controversia en los mismos términos en los que originariamente lo había hecho el Juzgado de lo Contencioso-Administrativo núm. 13 de Barcelona. De acuerdo con el Auto núm. 5954/2018, de 30 de mayo, por el que se admitió a trámite el recurso de casación, presentaban interés casacional objetivo para la formación de jurisprudencia las siguientes cuestiones: (a) posibilidad de anulación de un Acuerdo municipal relativo a cuestiones consideradas por la mayoría de los Concejales de la corporación como poseedoras de interés para el conjunto de los vecinos, pese a su desvinculación con respecto a las competencias legalmente atribuidas al municipio; (b) posible relevancia, a estos efectos, de la naturaleza política de la declaración controvertida; y (c) posible relevancia, nuevamente a estos efectos, de que el Acuerdo agote su eficacia en el mismo hecho de la declaración.

En primer lugar, el Tribunal Supremo realiza un importante esfuerzo argumentativo encaminado a la corrección del pronunciamiento del Tribunal Superior de Justicia en lo que hace a la caracterización de algunos de los contenidos del Acuerdo municipal controvertido como propios de un acto político sustraído a toda posibilidad de control jurisdiccional. En este sentido, con ánimo ciertamente pedagógico, efectúa un recordatorio de su propia jurisprudencia en relación con la superación, por imperativo constitucional y legal, de la vieja doctrina del acto político del Gobierno, subrayando cómo, pese a la no sujeción de dicha categoría de actos al Derecho administrativo, por tratarse los mismos de resoluciones por las que se adoptan decisiones típicamente directivas de la acción política con total libertad en cuanto a sus fines, es admisible -y obligado- el

\footnotetext{
4 FJ 2. ${ }^{\circ}$ de la Sentencia núm. 522/2017, de 26 de junio, del Tribunal Superior de Justicia de Cataluña.

5 FJ $3 .^{\circ}$ de la Sentencia.
} 
REALA. Nueva Época - N. 12, octubre-marzo 2019 - ISSN: 1989-8975 - DOI: 10.24965/reala.i12.10712 - [Págs. 152-164]

Nulidad radical de un Acuerdo municipal de apoyo al proceso soberanista catalán (Sentencia del Tribunal Supremo núm. 2088/2019..

control jurisdiccional de aquellos de sus elementos reglados que la jurisprudencia considera «judicialmente asequibles». A mayor abundamiento, prosigue el Tribunal Supremo, el hecho de que el artículo 2.a) de la LJCA no mencione los actos de las entidades locales al referirse a los sometidos a este peculiar régimen de control judicial es indiciario de las dificultades de admisión de su existencia en el ámbito local. De esta forma, concluye el Alto Tribunal afirmando la incorrección de la Sentencia objeto de recurso en este punto y la necesidad de acordar su casación ${ }^{6}$.

En conexión con lo anterior, razona a continuación el Tribunal Supremo sobre la (im)procedencia de la invocación de la doctrina afirmada en la STC 42/2014, de 25 de marzo, como fundamento de la restricción del alcance del control judicial del Acuerdo municipal controvertido. En este sentido, afirma que el peculiar contexto en el que la naturaleza política de la resolución objeto de fiscalización adquiría relevancia -se trataba de un procedimiento sustanciado de conformidad con lo establecido en el Título V de la Ley Orgánica 2/1979, de 3 de octubre, del Tribunal Constitucional (en adelante, LOTC)- hace que devengan irrelevantes, a los efectos del asunto de que conoce, las afirmaciones allí vertidas, por cuanto la lógica que sigue la admisibilidad en el orden contencioso-administrativo es autónoma con respecto a la de esta singular modalidad de proceso constitucional ${ }^{7}$. De ello resulta la inexistencia de espacios de actuación de los poderes públicos al margen de la ley, pues, de acuerdo con los artículos 9.1 y 103.1 de la Constitución, todas las Administraciones Públicas se encuentran positivamente vinculadas al principio de legalidad ${ }^{8}$.

De esta forma, los términos del recurso de casación son reformulados por el Tribunal Supremo, que orienta la resolución del mismo a la determinación de si el Acuerdo del municipio de Caldes de Montbui es o no acorde con el marco constitucional -concepto integrante aquí de las normas del bloque de constitucionalidad relevantes para la resolución del asunto, esto es, las disposiciones sobre Derecho local de rango constitucional y estatutario-, con el Derecho supranacional -se citan, a estos efectos, la Carta Europea de Autonomía Local de 15 de octubre de 1985 (en adelante, CEAL), el Convenio-Marco europeo sobre cooperación transfronteriza de 11 de mayo de 1980, comúnmente denominado Convenio de Madrid, y el Reglamento (CE) núm. 1082/2006, de 5 de julio, del Parlamento Europeo y del Consejo, sobre la Agrupación Europea de Cooperación Territorialy con la normativa legal definitoria de la autonomía local. Así, y a partir de una cita de la reiterada doctrina constitucional relativa a la forzosa toma en consideración, por parte del legislador ordinario, de la presencia de intereses locales y/o supralocales en la definición de las competencias del municipio, concluye el Tribunal Supremo la inexistencia de norma alguna en nuestro ordenamiento jurídico que conecte el contenido del Acuerdo controvertido con el interés de la comunidad local ${ }^{9}$. La exigencia de determinación legal de las competencias del municipio, consagrada ex artículo 25.2 de la LBRL, refuerza la anterior comprensión del problema ${ }^{10}$.

Lo expuesto fuerza al Tribunal Supremo a acordar la estimación del recurso de casación. Desecha, en este sentido, la diferenciación en que se basaba el Tribunal Superior de Justicia en relación con la impugnabilidad de la actuación administrativa en función de lo político de sus contenidos, de sus efectos y de su finalidad, declarando la necesidad de valoración conjunta del Acuerdo municipal, de la que resulta la falta manifiesta de competencia para su dictado, determinante de la estimación de su carácter nulo de pleno derecho. En aparente contradicción con el razonamiento inicial en relación con el análisis del fondo del asunto, los efectos prácticos directos y el contenido administrativo de la resolución adquieren inmediatamente, sin embargo, una relevancia decisiva en orden a acordar la aplicación de la sanción recién referida. El Acuerdo municipal que aboga por una alteración total de la organización territorial del Estado sin considerar siquiera la activación del procedimiento de reforma de la Constitución, prosigue el Alto Tribunal, es contrario a los principios de lealtad institucional (proclamado, en su formulación específicamente local, en el artículo 55 de la LBRL) y de objetividad de la actuación local (artículos 103.1 de la Constitución y 6.1 de la LBRL). Concluye en este punto el Tribunal Supremo subrayando la total desconexión de la cuestión tratada en el Acuerdo controvertido con el interés del municipio, al afirmar que «una Administración Pública no se puede manifestar en una materia de la trascendencia de la que aborda el acuerdo recurrido asumiendo una posición de parte e identificando con ella a la Corporación misma, mucho menos sin manifestar que la misma no se adopta con el acuerdo unánime de los miembros de la Corporación, que en este caso no ha existido» ${ }^{11}$.

\footnotetext{
6 FJ $2 .^{\circ}$ de la Sentencia núm. 2088/2019, de 26 de junio, del Tribunal Supremo.

FJ $4 .^{\circ}$ de la Sentencia.

FJ $5 .^{\circ}$ de la Sentencia.

9 FJ $60^{\circ}$ de la Sentencia.

10 FJ $7 .^{\circ}$ de la Sentencia.

11 FJ $8 .^{\circ}$ de la Sentencia.
} 
REALA. Nueva Época - N. ${ }^{0}$ 12, octubre-marzo 2019 - ISSN: 1989-8975 - DOI: 10.24965/reala.i12.10712 - [Págs. 152-164]

Nulidad radical de un Acuerdo municipal de apoyo al proceso soberanista catalán (Sentencia del Tribunal Supremo núm. 2088/2019..

En consonancia con los razonamientos referidos, el Tribunal Supremo acuerda la casación de la Sentencia del Tribunal Superior de Justicia, confirmando el pronunciamiento del Juzgado de lo Contencioso-Administrativo núm. 13 de Barcelona, y responde a las cuestiones que justificaban la identificación del interés casacional objetivo para la formación de jurisprudencia afirmando que (i) es ciertamente procedente la declaración de nulidad de un Acuerdo municipal de contenido eminentemente político que se presente carente de conexión con el círculo de intereses de la corporación y con las competencias legalmente atribuidas a la entidad local; que (ii) las declaraciones municipales de dicha naturaleza han de respetar el principio de vinculación positiva a la Constitución y al resto del ordenamiento jurídico; y que (iii) a estos efectos es irrelevante que la resolución en cada caso controvertida agote o no sus efectos en la propia declaración ${ }^{12}$.

\section{COMENTARIO CRÍTICO DE LA RESOLUCIÓN}

Descrita sumariamente la valoración de que es objeto el Acuerdo del Pleno del municipio de Caldes de Montbui de 28 de febrero de 2013 en las diversas instancias judiciales, procede en este momento abordar el comentario crítico de la reciente Sentencia del Tribunal Supremo núm. 2088/2019, de 26 de junio, por la que se ha declarado su nulidad de pleno derecho. Como ha quedado dicho en la Introducción del presente trabajo, son diversos los extremos de la argumentación desarrollada por el Tribunal Supremo que entendemos incorrectos o insuficientemente fundados. Al análisis crítico de los mismos se dedican las páginas que siguen, en las que se considerarán específicamente la debilidad -solo relativa- de la forma en que el Alto Tribunal excluye la aplicación de los límites de fiscalización jurisdiccional de los actos de gobierno al Acuerdo municipal controvertido (1), la cuestionable reconducción de los problemas jurídicos planteados a una comprensión no matizada de los principios de competencia y legalidad (2) y la criticable falta de toma en consideración de ulteriores extremos relevantes en la resolución del recurso de casación que da lugar al dictado de la Sentencia (3).

\section{Un rechazo certero, aunque un tanto tímido, de la aplicación de las restricciones del control jurisdiccional de los actos de gobierno}

Es claro que no procede ensayar aquí una reconstrucción de la compleja problemática relativa al concepto de acto político o de gobierno, categoría, esta, objeto en su día de un muy rico debate doctrinal y sujeta en la actualidad a un régimen de control jurisdiccional específico. El mismo se basa en el rechazo de la existencia de actos de las Administraciones Públicas que, por su carácter netamente político, no sean susceptibles de control jurisdiccional, pero, al mismo tiempo, consagra una limitación del alcance de dicha posibilidad de fiscalización con respecto a los mismos a la tutela de los derechos fundamentales, a la verificación del respeto de la disciplina aplicable a sus elementos reglados y a la determinación de las indemnizaciones a las que, en su caso, den lugar; tratamiento, en fin, del que exclusivamente pueden verse beneficiados los actos del Gobierno de la Nación y de los Consejos de Gobierno de las Comunidades Autónomas [artículo 2.a) de la $[J C A]^{13}$.

Es igualmente claro que la postura sostenida por el Tribunal Superior de Justicia de Cataluña en relación con la posible aplicación de la doctrina del acto de gobierno al Acuerdo municipal impugnado era manifiestamente incorrecta. Recuérdese, en este sentido, que el órgano jurisdiccional partía de la consideración de que la total falta de efectos jurídicos de los dos últimos apartados del Acuerdo conduciría a la imposibilidad de proceder a su control en sede jurisdiccional: el contenido de aquellos -neta, y ya no solo eminentemente, político- resultaría determinante de la exclusión de toda forma de fiscalización judicial. Ya desde una perspectiva general, la necesidad de desechar una tal conclusión se impone con evidencia: si bien es cierto que en ningún caso podría admitirse una sustitución judicial de la decisión, política, adoptada por el Pleno del Ayuntamiento de Caldes de Montbui, no lo es menos que en modo alguno nos encontramos ante una resolución no sometida al Derecho administrativo y que la hipótesis de su anulación jurisdiccional no se sustentaría en la mejor o peor consideración de que fuera merecedor, en términos metajurídicos, el contenido del

\footnotetext{
12 FJ $9 .^{\circ}$ de la Sentencia.

13 Sobre el contexto en el que se adoptó la regulación referida y los principales problemas interpretativos que la misma plantea, cfr. la sumaria pero muy clarificadora exposición de SANTAMARÍA PASTOR, J. A. (2010): La Ley reguladora de la Jurisdicción Contencioso-Administrativa: comentario, págs. 83-85. Madrid: lustel.
} 
REALA. Nueva Época - N. ${ }^{0}$ 12, octubre-marzo 2019 - ISSN: 1989-8975 - DOI: 10.24965/reala.i12.10712 - [Págs. 152-164]

Nulidad radical de un Acuerdo municipal de apoyo al proceso soberanista catalán (Sentencia del Tribunal Supremo núm. 2088/2019..

Acuerdo, sino en el examen del efectivo cumplimiento de los requisitos de validez aplicables a la totalidad de actos de las Administraciones Públicas -en concreto, de la competencia para su adopción, elemento reglado por excelencia-, entre los que, claro está, se encuentran también aquellos para cuya adopción las mismas disfrutan de amplios márgenes de discrecionalidad.

Al pronunciarse sobre la (in)corrección de la Sentencia del Tribunal Superior de Justicia en lo que hace a este concreto aspecto, el Tribunal Supremo, como ya hemos visto, centra los términos de la cuestión en la improcedencia de la aplicación de las restricciones al control judicial previstas en el artículo 2.a) de la LJCA por tratarse la resolución impugnada de un Acuerdo adoptado por el Pleno de un municipio, órgano al que el precepto mencionado no hace referencia. Sin embargo, el Alto Tribunal se muestra, a este respecto, menos tajante que en resoluciones anteriores, entre las que la mejor doctrina ${ }^{14}$ destaca la Sentencia de la Sección $4 .^{a}$ de la Sala $3 .^{a}$ de 24 de noviembre de 2003 (recurso de casación núm. 7786/00), en la que, con base en una interpretación literal del artículo 2.a) de la LJCA, se excluía a radice la consideración como acto de gobierno de un Acuerdo municipal de declaración de una empresa como persona non grata no solo en términos objetivos, sino también subjetivos, dada la autoría del mismo ${ }^{15}$. En la Sentencia objeto de comentario, sin embargo, la ausencia de mención de los órganos de gobierno de las entidades locales en el artículo 2.a) de la LJCA es considerada como mero «índice de la dificultad de que, al menos en principio, estos entes puedan adoptar acuerdos de orientación de su autogobierno en los que el contenido de la decisión sea enteramente libre en cuanto al fin» (énfasis añadido) ${ }^{16}$. Es obvio que el inciso reproducido, pese a la aplicación material, también en la resolución objeto de comentario, de la interpretación gramatical del artículo 2.a) de la LJCA, podría terminar abriendo en el futuro la puerta a una reconsideración de la cuestión, que se traduciría en una extensión del más laxo régimen de fiscalización jurisdiccional de los actos de gobierno a favor de algunos de los provenientes de las Administraciones locales.

La anterior vacilación del Tribunal Supremo en relación con la interpretación del tantas veces citado artículo 2.a) de la LJCA es debida, en nuestra opinión, a lo discutible de la redacción que el precepto incorpora. Admitida legalmente -y este es el incontrovertible dato del que ha de partirse- la existencia de actos cuya estrecha vinculación con la función de dirección política implica una forzosa (y, en todo caso, solo parcial) inhibición de la jurisdicción contencioso-administrativa en el desarrollo de su función de control sobre los mismos, la opción por excluir la aplicación del (por otro lado, y por diversos motivos, muy problemático) régimen referido a la totalidad de resoluciones de origen local parece difícilmente compatible con el principio constitucional de autonomía, pues hace de casi ínfima condición, particularmente, a la Administración municipal, en cuya labor netamente política están presentes las características de la que es propia de los niveles estatal y autonómico que justifican, de acuerdo con la decisión definitivamente adoptada por nuestro legislador procesal, la regulación del artículo 2.a) de la LJCA. No puede extrañar, así, que incluso se haya defendido, en ocasiones, la extensión de la categoría conceptual del acto de gobierno a algunos de los dictados por las instancias locales ${ }^{17}$. Desde otra perspectiva, y en conexión con lo anterior, debe subrayarse, en fin, que quienes se han mostrado más abiertamente favorables a la exclusión referida se han posicionado en este sentido no por considerar intrínsecamente diferente la tarea de gobierno local de sus equivalentes en los niveles estatal y autonómico, sino por su rechazo, perfectamente comprensible en términos constitucionales, de la idea de la existencia de ámbitos de la actuación administrativa no sujetos parcialmente al control judicial ${ }^{18}$.

Tales defectos, ello resulta evidente, no son imputables al Tribunal Supremo. Lo sorprendente de la Sentencia objeto de comentario en lo que hace a esta específica cuestión no es ya que la misma no tenga en cuenta la naturaleza esencialmente política de la declaración al razonar sobre su invalidez -aspecto sobre el que se volverá infra, en la segunda sección del presente epígrafe-, sino su falta de contundencia

14 Cfr. SANTAMARÍA PASTOR, J. A. (coord.) (2017): 1.700 Preguntas sobre Contencioso-Administrativo. Madrid: Lefebvre-El Derecho.

${ }^{15} \mathrm{FJ} 4 .^{\circ}$ de la Sentencia de 24 de noviembre de 2003 del Tribunal Supremo (recurso de casación núm. 7786/00).

16 FJ $2 .^{\circ}$ de la Sentencia núm. 2088/2019, de 26 de junio, del Tribunal Supremo.

17 En este sentido, vid., en relación, particularmente, con las declaraciones políticas de los órganos municipales, problemática a la que afecta la Sentencia objeto de análisis, GARRIDO CUENCA, N. (1998): El Acto de Gobierno: un análisis en los ordenamientos francés y español, págs. 595 y sigs. Barcelona: Cedecs; y BARATA I MIR, J. (1999): Los actos de gobierno en el ámbito municipal, págs. 81 y ss. Madrid: Tecnos.

18 En este sentido, véase, particularmente, MARTíNEZ LÓPEZ-MUÑIZ, J. L. (2002): "Actos de gobierno y Administración Local", en BAÑO LEÓN, J. M. ${ }^{a}$ y CLIMENT BARBERÁ J. (coords.): Nuevas perspectivas del Régimen Local: estudios en Homenaje al Profesor José M. ${ }^{a}$ Boquera Oliver, págs. 639-683 (passim y, especialmente, págs. 680-681). Valencia: Tirant lo Blanch. 
REALA. Nueva Época - N. 12, octubre-marzo 2019 - ISSN: 1989-8975 - DOI: 10.24965/reala.i12.10712 - [Págs. 152-164]

Nulidad radical de un Acuerdo municipal de apoyo al proceso soberanista catalán (Sentencia del Tribunal Supremo núm. 2088/2019..

al descartar la consideración del Acuerdo impugnado como acto de gobierno. Si la vertiente material de la resolución municipal recurrida ya es, por sí misma, motivo suficiente para la inaplicación del artículo 1.2 de la LJCA -el Acuerdo no deja de encontrarse sujeto, pese a lo eminentemente político de su contenido y a su inhabilidad para la producción de efectos jurídicos inmediatos, al Derecho administrativo, y de dicha premisa parte correctamente el Tribunal Supremo, y su adopción no está relacionada con la labor de dirección política de la corporación-, la perspectiva subjetiva -la autoría municipal del acto- conduce, en términos jurídicopositivos, a la exclusión inmediata de cualquier razonamiento ulterior en sentido contrario. Sobre la base de lo expuesto, el tono dubitativo del Tribunal Supremo en lo relativo a esta cuestión se nos antoja censurable, aun cuando, debemos insistir sobre ello, la decisión definitivamente adoptada sea la correcta.

A mayor abundamiento, debe tenerse en cuenta que el artículo 2.a) de la LJCA no se basa en la consideración de que los actos administrativos carentes de efectos jurídicos inmediatos no puedan o no deban ser objeto de un control jurisdiccional pleno: la ratio del citado precepto legal se encuentra, más bien, en la necesidad de circunscribir la posible fiscalización judicial a los aspectos en él mismo mencionados (lesión de los derechos fundamentales, elementos reglados e indemnizaciones procedentes) en presencia de resoluciones adoptadas por los Ejecutivos nacional o autonómicos en su labor de dirección política, para cuyo dictado los mismos disfrutan, por consiguiente, de los más amplios márgenes de actuación. Constantemente se adoptan, sin embargo, actos de tipo declamatorio y carentes de eficacia jurídica por sí mismos, que se agotan, por consiguiente, en una mera declaración, pero que se encuentran desconectados de la labor de dirección política de las respectivas entidades. En modo alguno es admisible en términos jurídico-constitucionales la exclusión o la limitación del control judicial ejercitable sobre los mismos: muy al contrario, este habrá de ser pleno, pues también la denominada actividad administrativa informal o material es apta para la consolidación de situaciones contrarias a Derecho -desde la perspectiva que aquí interesa, para la irrogación de perjuicios a diversos títulos competenciales estatales-, que lógicamente deben poder ser corregidas por los órganos de la jurisdicción ${ }^{19}$. En esta línea, no es otra la comprensión del problema de la que parte el legislador en la regulación de la actividad convencional transnacional de los sujetos de Derecho público diferentes de la Administración General del Estado, toda vez que la relativamente reciente Ley 25/2014, de 27 de noviembre, de Tratados y otros Acuerdos Internacionales, prevé la aplicación de mecanismos de control administrativo preventivo no solo con respecto a los denominados acuerdos internacionales administrativos, ejecutivos de un Tratado internacional de cobertura, sino también en lo que hace a los acuerdos internacionales no normativos, que carecen, por definición, de cualesquiera efectos jurídicos, precisamente a partir de la consideración de que de dicha circunstancia no se puede deducir la inhabilidad de los mismos para perjudicar las relaciones internacionales y la política exterior de la Nación.

En síntesis, el Tribunal Supremo, pese a alcanzar una conclusión correcta en lo que hace a la plena justiciabilidad del Acuerdo objeto de impugnación, no ha terminado de redondear la motivación de la estimación del recurso de casación de la Sentencia del Tribunal Superior de Justicia de Cataluña en lo que hace a esta específica cuestión, y ha introducido, de hecho, algún razonamiento en forma de obiter dictum que podría dar lugar a equívocos en el futuro. La naturaleza esencialmente política de la declaración no puede motivar, por sí misma, una retracción de la jurisdicción contencioso-administrativa en el ejercicio de la función de control que le es constitucional y legalmente encomendada. Ahora bien, el referido carácter sí incide, en nuestra opinión, en la forma en que deben aplicarse los principios de competencia y legalidad en la fiscalización de la actuación municipal. Veámoslo en detalle.

\section{Una aplicación no matizada y falta de precedentes de los principios de competencia y legalidad a la actividad meramente declamatoria de las entidades locales}

En nuestra opinión, la forma en que el Tribunal Supremo aplica los principios de competencia y de legalidad de la actuación de las Administraciones Públicas para acordar la declaración de nulidad del Acuerdo del Pleno del Municipio de Caldes de Montbui es el aspecto de la Sentencia que se revela más problemático. En esencia, el Tribunal Supremo apoya su argumentación en la dilución de la cláusula general de competencias que incorporaba el artículo 25.1 de la LBRL por obra de la Ley 27/2013, de 27 de diciembre, de racionalización y sostenibilidad de la Administración Local, y en la consiguiente necesi-

19 Sobre la cuestión, en general, vid. HUERGO LORA, A. (2011): "Del recurso contra la vía de hecho al recurso contra la actividad material de la Administración”, en Revista General de Derecho Administrativo, núm. 28, págs. 1-19. 
REALA. Nueva Época - N. 12, octubre-marzo 2019 - ISSN: 1989-8975 - DOI: 10.24965/reala.i12.10712 - [Págs. 152-164]

Nulidad radical de un Acuerdo municipal de apoyo al proceso soberanista catalán (Sentencia del Tribunal Supremo núm. 2088/2019..

dad de atribución legal de las competencias propias a las entidades municipales, así como en la falta de conexión de la problemática a la que se refiere el Acuerdo impugnado con los intereses locales y en el principio de vinculación positiva del conjunto de Administraciones Públicas a la Constitución y al resto del ordenamiento jurídico. Sobre la base de este razonamiento, el Alto Tribunal declara la nulidad de aquel por falta manifiesta de competencia, de conformidad con lo que hoy establece el artículo 47.1.b) de la Ley 39/2015, de 1 de octubre, del Procedimiento Administrativo Común de las Administraciones Públicas (en adelante, LPAC).

Tal visión del problema es, sin embargo, sesgada. El criterio competencial, tal y como delimitado por el Tribunal Supremo en la Sentencia -exigencia de atribución legal específica de la competencia de actuación y necesidad de conexión de la misma con los intereses específicamente locales-, no ha justificado nunca, por sí mismo, la invalidez de los acuerdos de las entidades locales de carácter meramente declamatorio. Desde siempre, particularmente las corporaciones municipales han llevado a cabo actuaciones -ya unilaterales, como en el caso controvertido, ya incluso de naturaleza convencional, como en el de los acuerdos de hermanamiento- desprovistas de efectos jurídicos y que afectaban a sectores de la realidad totalmente ajenos al elenco de competencias legalmente atribuidas a su favor y faltos de relación con el círculo de intereses loca$\operatorname{les}^{20}$. Las más de las veces, los niveles territoriales superiores se abstuvieron de reaccionar por considerarlas inofensivas a la vista de su contenido, que suscribían, así, implícitamente; en otras ocasiones, fueron los órganos de la jurisdicción los que confirmaron su validez pese a la efectiva constatación de la concurrencia de las circunstancias referidas. En este sentido, una importante y ya antigua línea jurisprudencial del propio Tribunal Supremo admitió la validez tanto de los posicionamientos como de las peticiones formuladas por las entidades locales a otras Administraciones con respecto a cuestiones sobre las que carecían absolutamente de competencias de actuación, poniendo de manifiesto, por medio de unos y de otras, sus diferentes visiones en relación con los problemas a los que en cada caso se referían ${ }^{21}$. El Alto Tribunal entendía, en definitiva, que intervenciones locales como las controvertidas no perseguían ni producían el efecto de una invasión competencial, sino que tan solo implicaban sendas contribuciones al debate público relativo a las cuestiones problemáticas que no condicionaban en absoluto la actuación de las Administraciones con potestades decisorias en las respectivas materias. En esta comprensión se basaba, de hecho, la representación procesal del Ayuntamiento de Caldes de Montbui, que defendía la reconducción del contenido del Acuerdo al ejercicio del derecho constitucional de petición.

El Tribunal Supremo debería haber atendido -no estimado, como se tendrá ocasión de argumentar infra, en la siguiente sección- esta alegación. El empleo inflexible del criterio competencial es, en primer lugar, contrario a una muy consolidada praxis institucional, favorable a -0 , cuando menos, permisiva en relación con- estas formas de actuación local, que habría de entenderse integrante, por este motivo, de la comprensión vigente del principio de autonomía, de acuerdo con la consideración del mismo, sostenida por nuestro Tribunal Constitucional ininterrumpidamente desde el inicio de su actividad, como garantía institucional. Al apartarse de su jurisprudencia previa -preciso es subrayarlo, de manera solo implícita, pues en la Sentencia no se hace mención de los pronunciamientos referidos- el Tribunal Supremo adopta una actitud que sorprende en un órgano jurisdiccional cuyos poderes se han visto reforzados mediante la reforma de la casación administrativa operada por la Ley Orgánica 7/2015, de 21 de julio, para garantizar el efectivo cumplimiento de la función nomofiláctica del referido recurso y, con ello, la certeza y previsibilidad en la aplicación del Derecho.

20 Al respecto, específicamente en relación con la relevancia de la tradición de la celebración de acuerdos de hermanamiento entre las ciudades europeas en la interpretación del principio de autonomía local, permítasenos la remisión a DÍAZ GONZÁLEZ, G. M. (2019): La acción exterior local. Bases constitucionales, págs. 36 y sigs., 235 y sigs. y 256 y sigs. Madrid: lustel.

21 Cfr. las Sentencias de la Sala 3. ${ }^{a}$ del Tribunal Supremo de 9 de febrero de 1987 (RJ\1987\2921, FJ 2. ${ }^{\circ}$ ), y de 8 de junio de 1987 (RJ1987\6102, FJ 5. ${ }^{\circ}$ ), sobre las que lúcidamente llaman la atención GARRIDO CUENCA, N. (1998: págs. 596-597) y BARATA I MIR, J. (1999: págs. 95 y sigs.). En el primer caso, se admitió la validez de la petición, formulada por el municipio de Valdobiño por virtud de un Acuerdo de 27 de octubre de 1983, de desnuclearización de su propio territorio, lo que, de acuerdo con el Tribunal Supremo, no implicaba la adopción de una auténtica decisión sobre una materia de competencia estatal, sino tan solo una petición dirigida al órgano competente para que adoptara la medida referida. En el segundo caso, el Tribunal Supremo declaró la validez jurídica del punto del Acuerdo del Ayuntamiento de Baracaldo de 27 de octubre de 1983 en el que se manifestaba la comprensión mayoritaria en la entidad con respecto a la instalación de determinados misiles en Europa, lo que, en opinión del Alto Tribunal, «solo [constituiría] una postura ideológica respecto de tal cuestión, en realidad atinente tan solo a los componentes de la Corporación que la han apoyado que, aunque discutible por su carácter subjetivo, es respetable, en cuanto manifestación de su parecer frente a quien puede hacer valer los derechos de España ante las potencias extranjeras interesadas, decidiendo atenderlo o desatenderlo según los intereses nacionales afectados, lo que significa que ninguna invasión de competencias existe en cuanto a este particular del acuerdo» (énfasis añadido). 
REALA. Nueva Época - N. 12, octubre-marzo 2019 - ISSN: 1989-8975 - DOI: 10.24965/reala.i12.10712 - [Págs. 152-164]

Nulidad radical de un Acuerdo municipal de apoyo al proceso soberanista catalán (Sentencia del Tribunal Supremo núm. 2088/2019..

Más allá de estas consideraciones, el entendimiento del principio de competencia en los términos referidos puede antojarse válido -e incluso deseable- a la vista del contexto jurídico-político en el que se dicta la resolución objeto de comentario, pero no lo es tanto si se consideran las limitaciones que del mismo se deducen en relación con las resoluciones de carácter exclusivamente declamatorio o con otras formas de actividad municipal desprovistas de efectos jurídicos inmediatos cuando los sectores de la realidad afectados no generan una controversia equiparable a la que rodea al proceso soberanista catalán. De consolidarse la doctrina afirmada en la Sentencia de 26 de junio de 2019 -lo que, a la vista de su íntegra reproducción posterior para la resolución de casos semejantes, puede considerarse ya efectivamente producido-, se petrificarían injustificadamente las posibilidades de participación local en el debate político y tendría lugar un retroceso en la interpretación del alcance del principio de autonomía no resultante de una mutación en la comprensión general del mismo por parte de la sociedad, único núcleo que goza de la máxima protección jurídica en nuestro sistema -de rango constitucional- de acuerdo con la doctrina de la garantía institucional. La necesidad de atribución por ley de competencias propias a los municipios que resulta de la redacción vigente del artículo 25.1 de la LBRL no puede, en definitiva, afectar, por sí misma, a actuaciones locales como la controvertida.

Lo anterior entronca con la lectura que en la Sentencia se hace del principio de vinculación positiva del conjunto de Administraciones Públicas a la Constitución y al resto del ordenamiento jurídico. La proclamación de aquel principio -al margen de las especialidades que afectan, precisamente, al ámbito local, como la relativa a la potestad reglamentaria ${ }^{22}$ - es, ciertamente, correlato necesario de la posición constitucional de la Administración, aun cuando no falte la razón a quienes, al constatar la inadecuación de una aplicación maximalista o inflexible de la referida doctrina a la totalidad de formas de actuación administrativa, han ensayado diversos intentos de relativización de la misma, asumidas incluso por algunas de las principales exposiciones generales de la disciplina del Derecho administrativo ${ }^{23}$. Al margen de esta reflexión de más amplio alcance, lo que en este momento interesa específicamente subrayar es que la rigidez a la que conduce la falta de incorporación de matizaciones al principio choca frontalmente con la tradicional aceptación de la praxis declamatoria e informal de las entidades locales. Nunca antes se había exigido para el desarrollo de la misma una conexión inequívoca con el propio ámbito competencial, como, en cambio, se hace en la resolución objeto de comentario, y ello porque no se había detectado, en casos en principio equiparables, por cuanto en ellos se resolvía sobre la validez de actuaciones carentes de efectos jurídicos inmediatos, lesión alguna de las competencias de otros niveles territoriales de poder. Y ello, conviene subrayarlo, pese a que las actuaciones en aquellos casos controvertidas ponían de manifiesto la diferente percepción de las entidades locales con respecto a la forma en que el Estado gestionaba sectores de la realidad de su sola competencia.

No convence, en fin, el rechazo de la aplicación de la doctrina constitucional, sentada en la STC $42 / 2014$, de 25 de marzo, relativa a que las meras manifestaciones institucionales que se opongan a lo establecido en la Norma Fundamental no deben dar forzosamente lugar a un pronunciamiento del Tribunal Constitucional. La razón de ser del mismo se encontraba, de acuerdo con la apreciación del Tribunal Supremo, en la falta de coincidencia de los contextos procesales en que aquella jurisprudencia había sido afirmada (procedimiento de impugnación de disposiciones sin fuerza de Ley y resoluciones de las Comuni-

22 De todos es sabido que, en relación con la potestad reglamentaria local, el Tribunal Supremo ha terminado por acoger la comprensión de su relación con la Ley en clave de vinculación negativa: en este sentido, pueden consultarse, entre otras muchas, las Sentencias de la Sala 3. a de 7 de octubre de 2009 (recurso de casación núm. 204/2008), de 17 de noviembre de 2009 (recurso de casación núm. 1168/2008), de 15 de diciembre de 2009 (recurso de casación núm. 496/2009) y de 24 de junio de 2014 (recurso de casación núm. 2500/2012), en las que el Alto Tribunal afirma que en su propia jurisprudencia «se abre paso la idea de una vinculación negativa, que permite a aquéllas [las entidades locales] sin previa habilitación legal actuar, dictando también ordenanzas, en toda materia que sea de su competencia, si al hacerlo no contradice ni vulnera la legislación sectorial que pudiera existir». Al respecto, en la doctrina pueden consultarse, sin ánimo de exhaustividad, las exposiciones de VELASCO CABALLERO, F. (2009): Derecho local: sistema de fuentes, págs. 241 y ss. Madrid: Marcial Pons; GALÁN GALÁN, A. (2010): "La consolidación del principio de vinculación negativa en el ámbito local", en Revista CEMCI Centro de Estudios Municipales y de Cooperación Internacional, núm. 8, págs. 1-27; EMBID IRUJO, A. (2011): "Ordenanzas y Reglamentos municipales", en MUÑOZ MACHADO, S. (dir.): Tratado de Derecho Municipal, vol. I, págs. 751 y ss.; especialmente, págs. 756 y sigs. Madrid: Iustel (3. ${ }^{a}$ edición); y FERNÁNDEZ-MIRANDA FERNÁNDEZ-MIRANDA, J. (2015): “EI principio de legalidad, la vinculación negativa y el ejercicio de la potestad reglamentaria local”, en Revista de Administración Pública, núm. 196, págs. 229-269.

23 Cfr., por todos, SANTAMARÍA PASTOR, J. A. (1991): Fundamentos de Derecho Administrativo, págs. 199 y ss. Madrid: Centro de Estudios Ramón Areces; y MUÑOZ MACHADO, S. (2015): Tratado de Derecho Administrativo y Derecho Público General, vol. III: Los principios de constitucionalidad y legalidad, pág. 101. Madrid: Agencia Estatal Boletín Oficial del Estado (4. ${ }^{a}$ edición). 
REALA. Nueva Época - N.12, octubre-marzo 2019 - ISSN: 1989-8975 - DOI: 10.24965/reala.i12.10712 - [Págs. 152-164]

Nulidad radical de un Acuerdo municipal de apoyo al proceso soberanista catalán (Sentencia del Tribunal Supremo núm. 2088/2019..

dades Autónomas, previsto en el artículo 161.2 de la Constitución y regulado en el Título V de la LOTC) y pretendía ser nuevamente aplicada (recurso contencioso-administrativo). Dicha constatación es incontestable, como también lo es, sin embargo, que la irreprochabilidad, en términos estrictamente jurídicos, de las meras declaraciones institucionales contrarias a un enunciado -o incluso a un principio- constitucional no resulta de las especialidades del procedimiento de impugnación previsto en el Título $V$ de la LOTC, sino de la asimilación de una concepción formal, no militante, del principio democrático en nuestro sistema: el entero texto constitucional puede ser objeto de revisión a través de los cauces procedimentales en él previstos, por lo que es perfectamente legítimo no solo que los diferentes partidos políticos manifiesten su desacuerdo con los contenidos de aquel, sino también que lo hagan las instituciones dotadas de legitimación democrática directa a través de actuaciones de naturaleza declamatoria, carentes de efectos jurídicos, cuando les falta la competencia para la implementación de la reforma correspondiente. Negar en abstracto esta posibilidad a los ayuntamientos supone, en definitiva, imponerles un alineamiento con la Constitución más allá de lo que se deduce de la misma, que consiste, a los efectos que aquí interesan, nada menos pero también nada más- que en la exigencia de respeto de los mecanismos de modificación de la Norma Suprema cuando se pretenda su alteración total o parcial.

Por consiguiente, recapitulando, de lo que se trataba en el pasado -en los remotos precedentes resueltos por el Tribunal Supremo en las Sentencias referenciadas- y habría debido tratarse al decidir sobre la impugnación del Acuerdo del Pleno del municipio de Caldes de Montbui, en último término, era de dilucidar si estas formas de actuación informal-declaraciones netamente políticas, peticiones dirigidas a otros entes públicos- de los ayuntamientos perjudica(ba)n la esfera competencial de otras Administraciones -especialmente, de la estatal- o si incurrían en alguna otra causa de invalidez material. En este sentido, entendemos que la expresión de una mera discrepancia ideológica o la formulación de la petición de que, en el tratamiento o en la gestión de una problemática política específica, se tengan en cuenta otros puntos de vista, no son, en modo alguno, lesivas per se del ámbito de competencias del ente territorial interpelado directa o indirectamente.

Ello no quiere decir, en todo caso, que no procediera, en el asunto que nos ocupa, la declaración de nulidad del Acuerdo municipal controvertido. Sin embargo, otros eran los motivos que conducían a dicha conclusión, que el Tribunal Supremo, incomprensiblemente, se ha abstenido de considerar. A los mismos habrá de hacerse breve referencia en las páginas que siguen.

\section{Un olvido patente de diversos criterios adicionales de argumentación}

Hasta aquí se ha defendido que no es exigible, de acuerdo con el marco jurídico-constitucional vigente y con el entendimiento tradicional del problema, que las manifestaciones netamente políticas de las entidades municipales, entendiéndose por tales las consistentes en meras declaraciones carentes de cualesquiera efectos jurídicos ulteriores, posean una conexión específica con los intereses locales o se basen en una atribución legal de la potestad específica para su adopción. El contenido de esta actividad declamatoria puede, por lo tanto, afectar a cualesquiera ámbitos de la realidad, y de esta forma de actuación administrativa pueden servirse las entidades locales para evidenciar la existencia de comprensiones contrarias al ordenamiento constitucional, en el sentido de que aboguen por una (procedimentalmente válida) revisión del mismo.

Esta última es la nota, esencial, que falta al Acuerdo municipal impugnado. Nuestro sistema, ciertamente, en contra de lo que desde el sector soberanista se viene constantemente defendiendo $-\mathrm{y}$ de lo que el propio Acuerdo municipal no se abstiene de afirmar- no criminaliza la ideología nacionalista ni la pretensión de constitución de la Comunidad Autónoma catalana como un Estado independiente. De todos es sabido, sin embargo, que la realización de dicha aspiración precisaría de una reforma constitucional y que los avances de las instituciones catalanas en aquella dirección han pretendido obviar este último aspecto, violentando gravísimamente el ordenamiento jurídico español por medio, además, de conductas posiblemente constitutivas de ilícitos penales a los que el Código vigente asocia penas privativas de libertad muy elevadas. La inequívoca adhesión a tal forma de proceder, a la que expresamente se da aliento en los apartados tercero y cuarto del Acuerdo impugnado, trasciende la mera manifestación de una visión que se aparta de la sostenida por los sucesivos Ejecutivos nacionales y la petición de una reconsideración de la manera en que se está gestionando el conflicto catalán: comporta, pura y simplemente, un ataque frontal al núcleo mismo de nuestro sistema jurídico y de nuestra convivencia, en lugar de promover su válida revisión, lo que sería plenamente legítimo. Este es el aspecto fundamental que conduce a la necesidad de declarar la nulidad de 
REALA. Nueva Época - N. 12, octubre-marzo 2019 - ISSN: 1989-8975 - DOI: 10.24965/reala.i12.10712 - [Págs. 152-164]

Nulidad radical de un Acuerdo municipal de apoyo al proceso soberanista catalán (Sentencia del Tribunal Supremo núm. 2088/2019..

pleno derecho del íntegro Acuerdo recurrido -y no solo de los pasajes del mismo aptos para la producción de auténticos efectos jurídicos, en los que se reconocían la soberanía y la independencia de Cataluña-, que el Tribunal Supremo, al adoptar la restrictiva visión de las posibilidades de actuación meramente declamatoria de las entidades municipales que ya hemos criticado supra, se abstiene de considerar con la profundidad que habría sido deseable. En conclusión, los municipios pueden, efectivamente, manifestar solemnemente la comprensión, mayoritaria en su seno, en relación con problemas políticos del más amplio alcance, incluso aunque ello suponga contradecir la postura adoptada por las instancias competentes para la adopción de las correspondientes decisiones; lo que no pueden hacer, en cambio, es, dicho en román paladino, promover que el entero sistema salte por los aires. Con independencia de que otras implicaciones deducidas a partir del mismo sean discutibles, aquí sí alcanza inequívocamente el principio de vinculación positiva a la legalidad de las Administraciones Públicas.

De otra parte, y a mayor abundamiento, tampoco tiene en cuenta el Alto Tribunal que la dimensión internacional del conflicto soberanista cualifica el exceso competencial en que incurre el ayuntamiento de Caldes de Montbui al adoptar el Acuerdo de adhesión al procès. Lo que en origen era un conflicto político doméstico ha terminado por traspasar nuestras fronteras, considerados, entre otros, factores tales como el intento de justificación en el Derecho internacional público de la autodeterminación de Cataluña -tajantemente rechazado por la doctrina internacionalista en bloque ${ }^{24}$ - o el de determinados políticos independentistas, procesados por los hechos de todos conocidos, de acceder a cargos representativos del Estado en instituciones supranacionales. De resultas de todo ello, la estrategia adoptada por el Gobierno central en el contexto internacional ha adquirido una extraordinaria relevancia para la solución del conflicto, razón por la cual la actividad de las entidades locales que resulte apta para debilitar la política exterior puesta en marcha por nuestro Estado para la defensa de su soberanía y de su integridad territorial debe considerarse inválida por vulnerar los artículos 97 y 149.1.3. ${ }^{a}$ de la Constitución ${ }^{25}$. Al abstenerse de tener en cuenta esta última perspectiva, el Tribunal Supremo no solo ha ignorado un importante elemento de refuerzo de la materialmente correcta conclusión que ha alcanzado en la resolución del recurso de casación interpuesto frente a la Sentencia del Tribunal Superior de Justicia de Cataluña, sino que también ha desaprovechado una oportunidad óptima para sentar unas bases doctrinales mínimas en relación con los límites jurídico-constitucionales de la acción exterior de las entidades locales, manifiestamente precisados de una mejor definición jurisprudencial.

\section{CONCLUSIONES}

Por virtud de la reciente Sentencia núm. 2088/2019, de 26 de junio, la Sala 3. ${ }^{a}$ del Tribunal Supremo ha declarado la nulidad radical del Acuerdo del Pleno del municipio de Caldes de Montbui en el que, además de reconocer la independencia y soberanía de Cataluña, aquel declaraba su adhesión al reto político representado por el procès y dirigía al Parlament y a los restantes ayuntamientos catalanes sendas peticiones de avance en la hoja de ruta independentista y de apoyo a la misma, respectivamente. Pese a que no pudiera ser otra la resolución del conflicto, la argumentación en que se apoya el Alto Tribunal es en diversos extremos incorrecta e incluso perniciosa, por cuanto, elevada a regla general, comportaría la automática invalidez de cualesquiera manifestaciones o declaraciones institucionales de las entidades locales, carentes de efectos jurídicos, por el solo hecho de no referirse a cuestiones de su competencia. Como hemos visto, no es esta la comprensión tradicional del problema ni son las exigencias afirmadas por el Tribunal Supremo en relación con esta forma de actividad local acordes con su propia jurisprudencia. Con seguridad han hecho mella en el ánimo del Alto Tribunal la enorme significación política del conflicto de fondo y el cuestionamiento constante de la vinculatoriedad del marco jurídico-constitucional español por parte de las fuerzas políticas soberanistas y de los sectores de la sociedad que las apoyan. Podrá convenirse ideológicamente con un puñetazo en la mesa como este, pero a los estudiosos del Derecho compete alertar de lo arriesgado de los apartamientos imprevistos e inmotivados con respecto a los criterios de interpretación de los principios jurídicos esenciales, máxime cuando tales golpes de timón provienen del tribunal que se sitúa en la cúspide de nuestra organización judicial.

24 Cfr. SÁENZ DE SANTA MARÍA, P. A. et al. (2018): "Declaración sobre la falta de fundamentación en el Derecho Internacional del referéndum de independencia en Cataluña”, en Revista Española de Derecho Internacional, vol. 70, núm. 1, págs. 295-298. DOI: http://dx.doi.org/10.17103/redi.70.1.2018.3.03.

25 Sobre el particular, desde una perspectiva general, vid., in extenso, DÍAZ GONZÁLEZ, G. M. (2019: págs. 247 y ss.). 
REALA. Nueva Época - N. ${ }^{0}$ 12, octubre-marzo 2019 - ISSN: 1989-8975 - DOI: 10.24965/reala.i12.10712 - [Págs. 152-164]

Nulidad radical de un Acuerdo municipal de apoyo al proceso soberanista catalán (Sentencia del Tribunal Supremo núm. 2088/2019..

Gustavo Manuel Díaz González

\section{BIBLIOGRAFÍA}

BARATA I MIR, J. (1999): Los actos de gobierno en el ámbito municipal. Madrid: Tecnos.

DÍAZ GONZÁLEZ, G. M. (2019): La acción exterior local. Bases constitucionales. Madrid: Iustel.

EMBID IRUJO, A. (2011): “Ordenanzas y Reglamentos municipales”, en MUÑOZ MACHADO, S. (dir.): Tratado de Derecho Municipal, vol. I, págs. 717-778. Madrid: Iustel (3. ${ }^{a}$ edición).

FERNÁNDEZ-MIRANDA FERNÁNDEZ-MIRANDA, J. (2015): "El principio de legalidad, la vinculación negativa y el ejercicio de la potestad reglamentaria local”, en Revista de Administración Pública, núm. 196, págs. 229-269.

GALÁN GALÁN, A. (2010): "La consolidación del principio de vinculación negativa en el ámbito local", en Revista CEMCI Centro de Estudios Municipales y de Cooperación Internacional, núm. 8, págs. 1-27.

GARRIDO CUENCA, N. (1998): El Acto de Gobierno: un análisis en los ordenamientos francés y español. Barcelona: Cedecs.

HUERGO LORA, A. (2011): "Del recurso contra la vía de hecho al recurso contra la actividad material de la Administración”, en Revista General de Derecho Administrativo, núm. 28, págs. 1-19.

MARTÍNEZ LÓPEZ-MUÑIZ, J. L. (2002): “Actos de gobierno y Administración Local”, en BAÑO LEÓN, J. M. a y CLIMENT BARBERÁ J. (coords.): Nuevas perspectivas del Régimen Local: estudios en Homenaje al Profesor José M. ${ }^{a}$ Boquera Oliver, págs. 639-683. Valencia: Tirant lo Blanch.

MUÑOZ MACHADO, S. (2015): Tratado de Derecho Administrativo y Derecho Público General, vol. III: Los principios de constitucionalidad y legalidad. Madrid: Agencia Estatal Boletín Oficial del Estado (4. ${ }^{2}$ edición).

SÁENZ DE SANTA MARÍA, P. A.; GARZÓN CLARIANA, G.; MANGAS MARTÍN, A.; PONS RAFOLS, X.; REMIRO BROTÓNS, A.; DEL VALLE GÁlVEZ, A. y ARENAS GARCÍA, R. (2018): "Declaración sobre la falta de fundamentación en el Derecho Internacional del referéndum de independencia en Cataluña", en Revista Española de Derecho Internacional, vol. 70, núm. 1, págs. 295-298. DOI: http://dx.doi.org/10.17103/redi.70.1.2018.3.03.

SANTAMARÍA PASTOR, J. A. (1991): Fundamentos de Derecho Administrativo. Madrid: Centro de Estudios Ramón Areces.

SANTAMARÍA PASTOR, J. A. (2010): La Ley reguladora de la Jurisdicción Contencioso-Administrativa: comentario. Madrid: lustel.

SANTAMARÍA PASTOR, J. A. (coord.) (2017): 1.700 Preguntas sobre Contencioso-Administrativo. Madrid: LefebvreEI Derecho.

VELASCO CABALLERO, F. (2009): Derecho local: sistema de fuentes. Madrid: Marcial Pons. 